\title{
An instrumental earthquake catalogue for the offshore Maltese islands region, 1995-2014
}

\author{
Matthew R. Agius* ${ }^{* 1,2}$, Pauline Galea ${ }^{1}$, Daniela Farrugia ${ }^{1}$ and Sebastiano D’Amico ${ }^{1}$ \\ (1) Department of Geosciences, University of Malta, Msida, Malta \\ (2) Now at Department of Sciences, University of Roma Tre, Rome, Italy
}

Article history: received November 11, 2019; accepted May 6, 2020

\begin{abstract}
We present the first instrumental earthquake catalogue for Malta using 20 years of broadband seismic data recording. For about two decades Malta had only one station (WDD) which formed part of regional networks. Its location in the eastern part of the Sicily Channel puts the station at the periphery of these networks with the result that weak, off-shore earthquakes that occur between Malta and Libya, are in many cases recorded on WDD only and are undetected or unlisted by the regional networks. We adopt the single-station earthquake location method to process the continuously recorded seismic data of station WDD from 1995 to 2014. We combine our earthquake list with the bulletins of INGV and IRIS to catalogue 550 earthquakes. We statistically quantify the uncertainties of the earthquake epicentres and establish that many earthquake locations differ from INGV/IRIS locations by $<20 \mathrm{~km}$ at local epicentral distances from WDD and that earthquake magnitudes determined from single station are overestimated by 0.2 . We find that the Malta and Linosa grabens are seismically active, and a high concentration of seismic activity is located $80-120 \mathrm{~km}$ SSE of Malta at around $35^{\circ} \mathrm{N}$ latitude. Closer to land, clusters of epicentres are also located, within $40 \mathrm{~km}$ to the east and south of Malta. This new earthquake catalogue shows that the regional seismicity is higher than previously observed and that a number of submarine structures in the area are active as part of the ongoing extension in the Sicily Channel.
\end{abstract}

Keywords: Malta; Earthquake catalogue; Central Mediterranean; Sicily Channel; Single station.

\section{Introduction}

Historically, national earthquake bulletins are maintained by local observatories and shared with international agencies to compile global catalogues, which are then used by seismologists to understand better global and regional seismicity and their associated tectonic regimes. Regions where the seismicity takes place across different national territories require a collective effort from different agencies in order to carry out effective monitoring. This is the case in the Sicily Channel, Central Mediterranean, located between the coasts of Sicily (Italy), Tunisia, Libya, and Malta (Figure 1). This area forms part of a region of complex tectonics whose geodynamic properties and behaviour are still being uncovered and discussed. Monitoring the seismicity inside the Channel is crucial to understand the tectonic processes taking place there and the associated hazards for citizens living in the area. 
Most authors agree that the overall tectonic regime is one of compression, resulting from the north-westward push of Nubia towards Europe, and exemplified by the Maghrebian thrust belt, which overlaps the simultaneously active and almost orthogonal normal fault system producing the Sicily Channel rift grabens [see e.g., Corti et al., 2006; Nocquet, 2012], in a typical extensional scenario. Using GPS data to study the present-day kinematics of the Europe-Africa plate boundary, Serpelloni et al. [2007] imply the presence of possible microplates in the region, in particular, the Sicily-Pelagian shelf domain which appears to be moving independently from Nubia. This microplate is proposed on the basis of a dextral, decoupling extension zone represented by the Strait of Sicily and TunisiaLibya rifts. The GPS velocity studies show the divergence between stations located on Lampedusa and Noto (Sicily) of around $1.5 \pm 0.5 \mathrm{~mm}$ /year [Serpelloni et al., 2007] (Figure 1). The extensional nature of the Sicily Channel is described by several authors in terms of a dextral shear wrench regime, stretching from the Ionian basin to the Maghrebian thrust front [Jongsma et al., 1985; Reuther, 1990; Serpelloni et al., 2007].

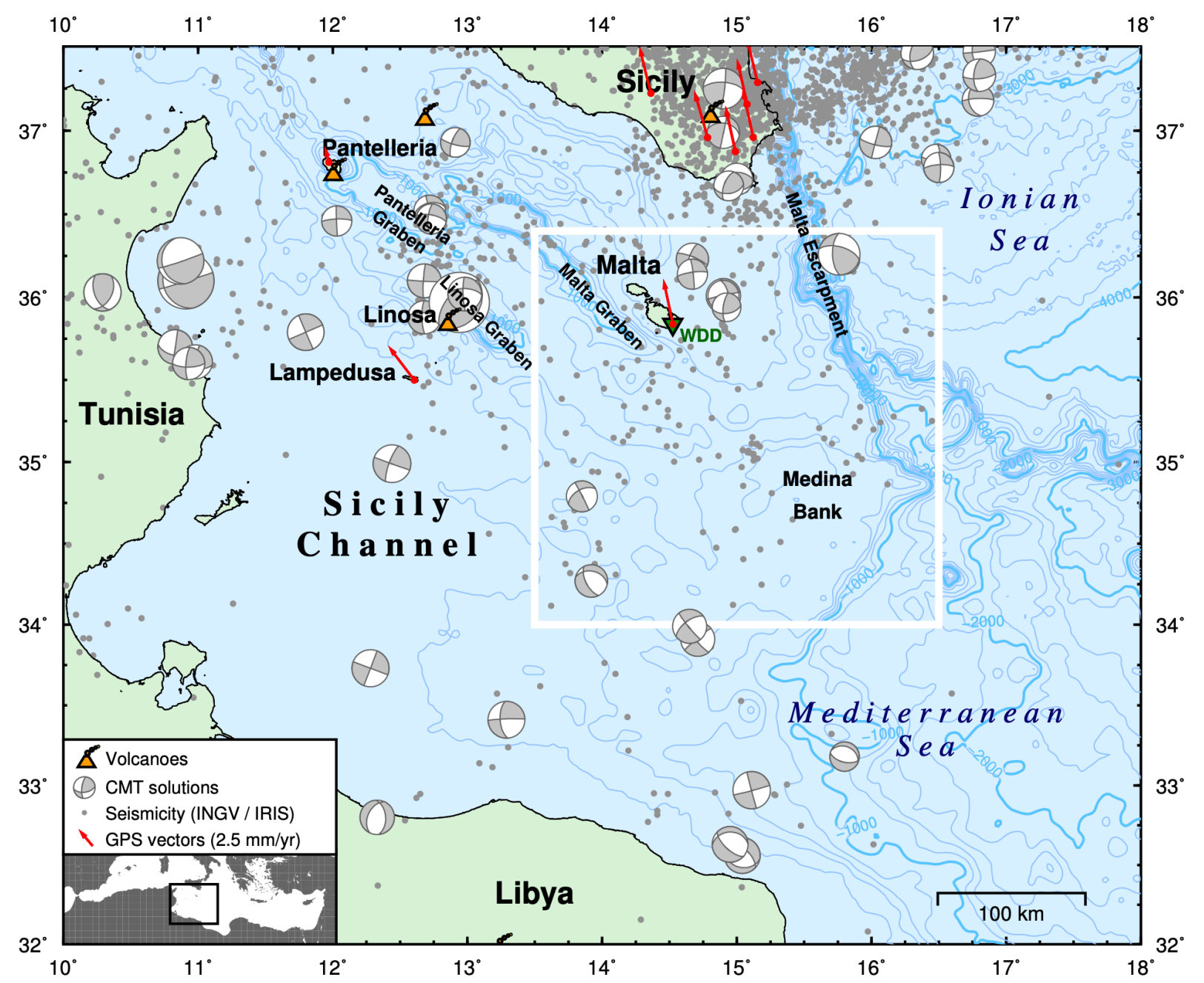

Figure 1. The seismo-tectonics of the Sicily Channel characterised by a system of grabens. Grey dots are earthquakes listed in the INGV and IRIS catalogues from 1995 to 2014. Beach balls are Centroid Moment Tensor (CMT) solutions of earthquakes from the global catalogue (http://www.globalcmt.org/ Dziewoński et al., 1981; Ekström et al., 2012) and from the European-Mediterranean CMT Catalogue (Pondrelli et al., 2002, 2004, 2007, 2011; D’Amico, 2014; Neri et al., 2018, http://www.bo.ingv.it/RCMT). Regional volcanoes are marked with orange symbols (Global Volcanism Program, 2013). Red arrows are Global Positioning System (GPS) horizontal velocity vectors with respect to fixed Eurasia (Devoti et al., 2011). Thick and thin blue contours mark the depth at every 1000 and 200 metres, respectively. White box indicates the study region. Inset map shows the area on a regional map. 
The grabens within the Sicily Channel are themselves defined by normal boundary faults with clear sub-vertical throws observable in seismic reflection lines [Gardiner et al., 1995; Dart et al., 1993; Corti et al., 2006]. At the same time, a number of connecting strike-slip faults affect the region and control the shear-dominated graben formation and extension [e.g., Reuther and Eisbacher, 1985; Cello, 1987]. Earthquake fault plane solutions from available databases seem in fact to be dominated by strike-slip mechanisms (Figure 1).

While the geology, geodynamics, and volcanism of the area have been adequately discussed [see e.g., Dart et al., 1993; Gardiner et al., 1995; Catalano et al., 2008b,a; Civile et al., 2010], seismicity has never been fully addressed, in spite of the fact that active tectonic features play an important role in the geodynamics of the whole region, and that seismological data can provide an extra dimension of knowledge.

The Sicily Channel has always been considered as an area of low and sparse seismicity. This is mostly due to the fact that earthquake magnitudes are small to moderate, and that instrumental coverage of the Channel has generally been poor. This situation improved considerably with the introduction of seismic stations on the islands of Pantelleria and Lampedusa by the Italian National Network in the 1980's and 1990's, the installation of a digital broadband seismic network across the Mediterranean (MedNet) including Malta with station WDD in 1995 [Boschi and Morelli, 1994], and recently by the online availability of three Tunisian stations and the setup of the permanent Malta Seismic Network [Agius et al., 2015b]. Still, a large proportion of the seismicity occurs to the south of the Maltese islands resulting either in an earthquake-station azimuthal gap larger than $200^{\circ}$ affecting the accuracy of earthquake location or simply out of reach of land-based networks (Figure 1).

Past research, processing a few years of data, showed a higher level of seismicity than previously reported [Agius and Galea, 2011; Agius et al., 2014], and that a number of submarine structures in the area are active. In this paper, we analyse 20 years of data recorded between 1995 and 2014 from broadband station WDD (Figure 1), which was the only station on the archipelago prior to the installation of the Malta Seismic Network. It was also the closest station to the seismic activity occurring in the study area (white box in Figure 1), and in most cases, the only station to record the events. In this process, we compile a comprehensive list of earthquakes for the area and present the first national instrumental earthquake catalogue for Malta.

\section{Data and Methodology}

We use the continuously recorded data of seismic station WDD which was installed in 1995 in Wied Dalam, Malta, as part of MedNet (MN) seismic network, and officially managed by the Istituto Nazionale di Geofisica e Vulcanologia (INGV), Rome [Boschi and Morelli, 1994]. MedNet was designed to contribute to the broadband instrumental coverage of the Mediterranean, improve our knowledge of the structure and dynamics of this region, and work towards the goal of minimisation of earthquake losses. Station WDD is a digital, 3-component, verybroadband system and consists of an STS-2 triaxial seismometer and a Quanterra Q680 data acquisition system. The seismograph, housed in a disused tunnel, is located at $35.8373^{\circ} \mathrm{N} 14.5242^{\circ} \mathrm{E}$.

The seismic data analysis presented here is based on the classic single-station earthquake location method combining a STA/LTA function and $P$-wave polarisation. We use LESSLA (Local Earthquake Single-Station Location Analyser, Agius and Galea, [2011]), an in-house software for automatic processing and interactive manual reprocessing. Events are detected using sensitive STA/LTA time windows running on 9 streams belonging to 3 different sampling frequencies 80, 20, and 1 sample per second (channels $\mathrm{HH}, \mathrm{BH}$, and LH, respectively) and their respective east-west, north-south, and up-down components (E, N, and $\mathrm{Z}$ ). The $P$ and $S$ phases are determined from the clustering of coincident weighted picks and amplitude-based assumptions. The earthquake origin time and epicentre distance from station WDD are then determined from locally-calibrated relationships of $S$ - $P$ interval with origin time and distance, respectively [Agius and Galea, 2011], whereas the back-azimuth direction is estimated from the three-component polarisation at the $P$ phase arrival [Roberts et al., 1989]. Thus, for each event, three back-azimuths are estimated, one for each stream. An estimate for the signal coherence is also determined.

Special attention was taken in applying the appropriate filters and time-windows necessary for the different sampling frequency streams because these are critical for the sensitivity of the algorithm [Agius, 2007; Agius and Galea, 2011]. A high pass filter with cut-off frequency at 2.5 and $0.5 \mathrm{~Hz}$ was used for the $\mathrm{HH}$ and BH channel, respectively, and a Butterworth bandpass filter with a frequency range of $0.05-0.1 \mathrm{~Hz}$ was used for the LH channel. All filtering was implemented using SAC [Seismic Analysis Code, Goldstein et al., 2003] libraries. 


\section{Matthew R. Agius et al.}

Figure 2 shows an example of an event processed by LESSLA. The top 3 traces are the filtered HHE, HHN and HHZ seismograms, followed by the polarisation (back-azimuth) and coherence estimates. The following traces are for the corresponding BH and LH streams, respectively. The step-like graphs of the back-azimuth and coherence reflect the width of the processed time windows set at 0.75 seconds for the $\mathrm{HH}$ channel, $3 \mathrm{~s}$ for BH, and $60 \mathrm{~s}$ for $\mathrm{LH}$, and time steps at half the time windows length. The $\mathrm{O}$ and $\mathrm{F}$ markers indicate the origin and end of phase time (Fini) of the event, whereas the $\mathrm{P}$ and $\mathrm{S}$ mark the arrivals of the seismic phases. The $S$ - $P$ time of $4.047 \mathrm{~s}$ yields a distance of 31.4 $\mathrm{km}$ away from the station WDD. The polarisation analysis at the $P$ arrival of all the three streams show that the event has a back-azimuth pointing towards the north-east direction (See Figure $4 \mathrm{~b}$ for earthquake location). Interestingly, one can also see the polarisation change at the $S$ arrival roughly by $90^{\circ}$ due to the transverse wave arriving on the horizontal components. Also, at the $P$ arrival, channels $\mathrm{HH}$ and $\mathrm{BH}$ show a peak in the coherence $(\mathrm{HH}>\mathrm{BH})$ indicating that the seismic phase is a coherent signal on the three components [Agius and Galea, 2011].

HPazi: 43.1 BPazi: 23.5 LPazi: 75.2

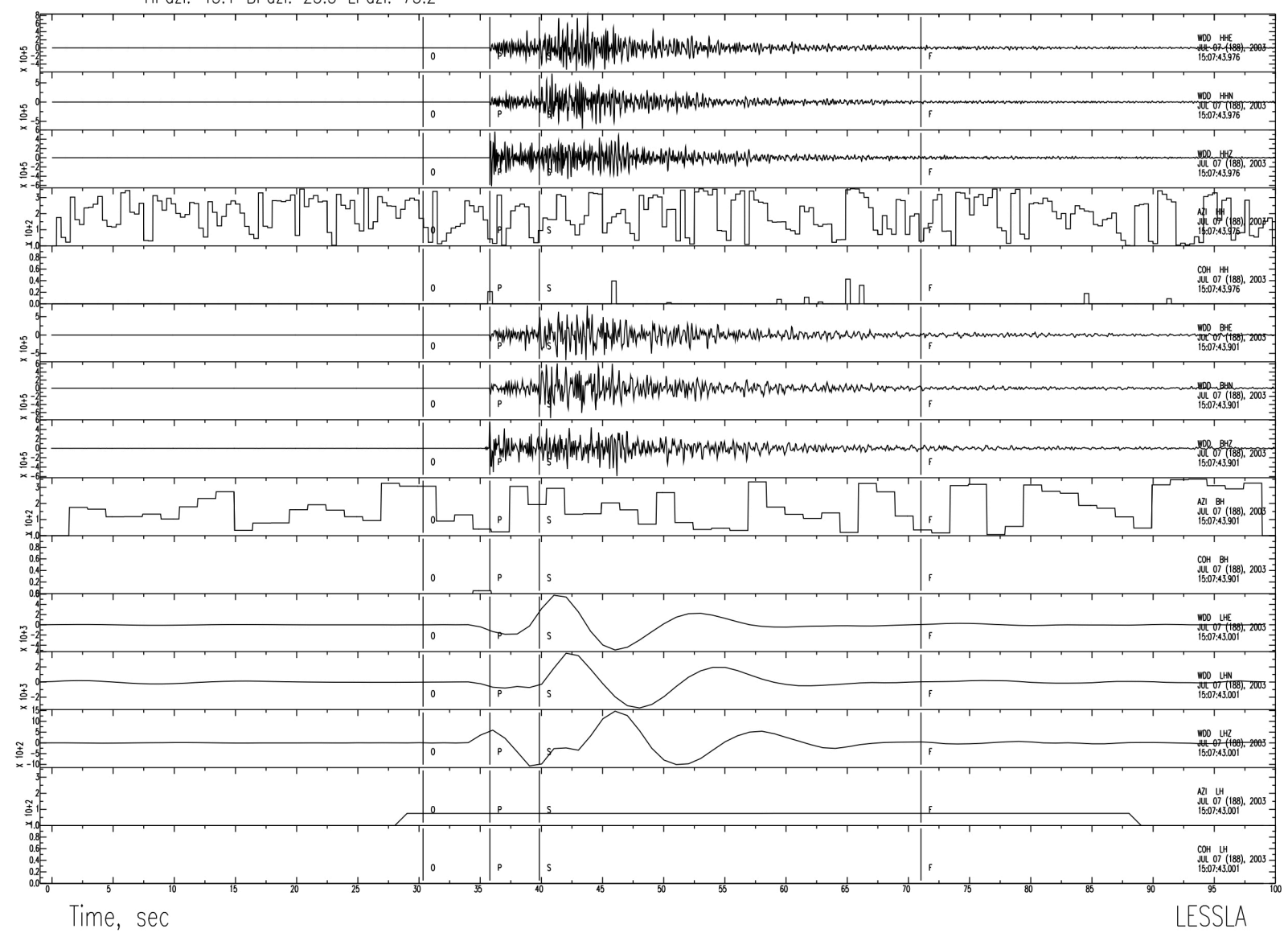

Figure 2. Example of a magnitude $4.6\left(\mathrm{M}_{L}\right)$ earthquake that struck about $31 \mathrm{~km}$ north-east off Malta on the $7^{\text {th }}$ of July, 2003 at 15:08:14 (UTC) processed using LESSLA. Top 3 waveforms are the HHE, HHN and HHZ filtered components followed by the back-azimuth $\left(0-360^{\circ}\right)$ and coherence estimates ( $\left.0-1\right)$ respectively. Rows $6-10$ and 11-15 are the corresponding waveforms and estimates for BH and LH streams, respectively. O, P, S, and F mark the origin time, the arrival of the $P$ and $S$ phases, and the end of the earthquake, respectively. The estimated back-azimuth at the $P$ phase arrival for the $\mathrm{HH}, \mathrm{BH}$ and $\mathrm{LH}$ are indicated on top. See Section 2.1 for details on the selection of the back-azimuth. Earthquake location is shown in Figure $4 \mathrm{~b}$.

The local and duration magnitudes, $\mathrm{M}_{L}$ and $\mathrm{M}_{D}$, are determined automatically for each event, the former using a Wood-Anderson adjusted local magnitude formula for southern California based on the maximum recorded horizontal displacement [Richter, 1935], and the latter using the time difference between the $P$ arrival and the event end [Scerri, 2001]. The two magnitudes are in general similar to each other with differences of less 
than 1.0, however, the duration magnitude has a strong dependence on the signal-to-noise ratio (SNR) and the waveform envelope, which affect the event de-trigger from the STA/LTA. We thus present here the local magnitude estimates. A detailed description and performance evaluation of LESSLA can be found in Agius and Galea [2011].

The seismic data from 07/07/1995 to 12/08/2014 recorded on station WDD was processed in batch using LESSLA (Figure 3). Unfortunately, up until 1999, the HH stream data is not available, mainly because of data storage and transmission limitations at that time. Thus, most of the analysis prior to this time is based on the BH stream. The automatic processing from LESSLA generated a list of thousands of events triggered by teleseismic, regional and local earthquakes, quarry blasts, and also false events. Each event was manually checked; false events were discarded and the remaining 5527 events were classified accordingly. The $P, S$ and $\mathrm{F}$ markers of each of the local events were re-picked manually and the earthquake parameters redetermined.

\section{Earthquake time series 1995-2014}

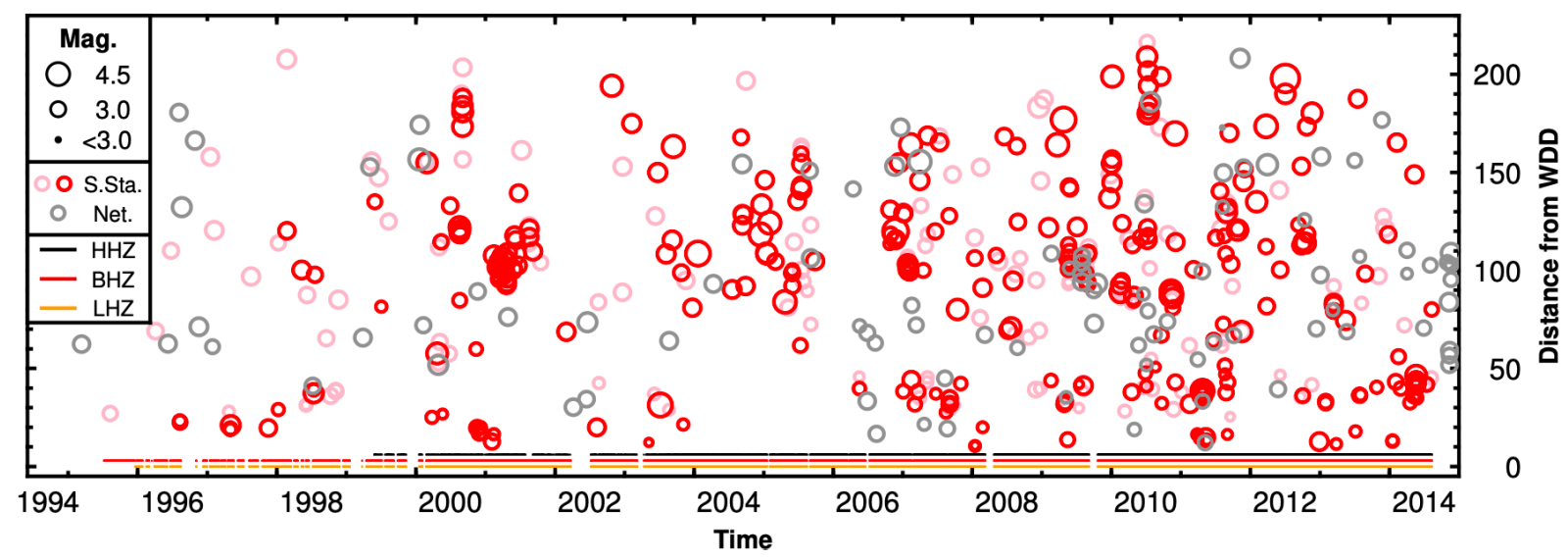

Figure 3. Earthquake time series of the merged bulletins sorted by distance from seismic station WDD. Each circle represents a unique earthquake. Red and pink circles are good and poor earthquake locations processed using single-station analysis (S.Sta.), respectively, whereas grey circles are locations from network solutions (Net.: INGV and IRIS). The coloured horizontal lines mark the data availability for the different channels of station WDD. See also Figure S3.

\subsection{Back-azimuth selection and quality of earthquake location}

The main weakness of a single-station earthquake location is the back-azimuth determination. The polarisation estimation of the first seismic phase arrival is frequency and amplitude dependent and is quickly contaminated with the arrival of new coda. In general, the back-azimuths estimated from different streams will differ and the final choice is subjective. In this paper, the back-azimuth estimate was selected based either on the channel which showed the highest coherence peak at the $P$ arrival, or the stream with the strongest SNR, or the longest stable azimuth (typically that of the BH stream). For example, in Figure 2 the back-azimuth of the three streams show quite a robust direction, with all three pointing towards the north-eastern quadrant. The selected back-azimuth is from the $\mathrm{HH}$ stream because of the corresponding high coherence at the $P$-phase arrival.

A quality grade was assigned to each event. Quality “A” indicates a very confident earthquake location in which the recorded event has a high SNR, clear $P$ and $S$ phase arrivals, and robust back-azimuth approximation, where $\mathrm{HH}$ and $\mathrm{BH}$ estimates are within the same quadrant $\left(<90^{\circ}\right)$. Figure 2 is an example of a quality "A" earthquake seismogram. A quality "B" was assigned to seismograms which had good $P$ and $S$ picks and thus a good distance evaluation but less robust back-azimuth estimates, with very different $\mathrm{HH}$ and BH polarisation estimates (e.g., Figure S1). A quality "C" was assigned to waveforms which had unclear arrival picks due to emergent phases and/or low SNR, resulting in an inaccurate distance, back-azimuth and thus location estimate (e.g., Figure S2). In this study, only earthquakes graded with quality “A” and “B” are presented and discussed. 


\subsection{Comparison with network locations}

We compare the single-station locations with those listed in the bulletins of INGV and Incorporated Research Institutions for Seismology (IRIS) (Figure 4a). The two catalogues do not always list the same events particularly for earthquakes which fall outside Italian coverage. The single-station analysis shows a more comprehensive picture of the seismicity in the region which is located in distinct regions within the study area. While all the bulletins complement each other we keep into consideration that there are location inaccuracies and inconsistencies for the same earthquakes. For example, some groups of earthquakes located using the single-station method are, on closer inspection, often aligned along arcuate lines, reflecting equal distance from WDD but a back-azimuth variability from the $P$-wave polarisation (e.g., earthquake swarms with approximately equal distance from station WDD but having a varying latitude and longitude, Figure S3). On the other hand, in some cases, the network locations disagree with the expected distance from station WDD inferred from the seismograms. For instance, the location of the earthquake shown in Figure 2 is very different from that reported by INGV (Figure $4 \mathrm{~b}$ ). The $S$ - $P$ time difference of $4.047 \mathrm{~s}$ suggests that the earthquake is close to the station WDD and the $P$-wave polarisation indicates it is from the north-east direction, contrary to the more distant south-east location listed by INGV.

\section{Comparison between earthquake bulletins}
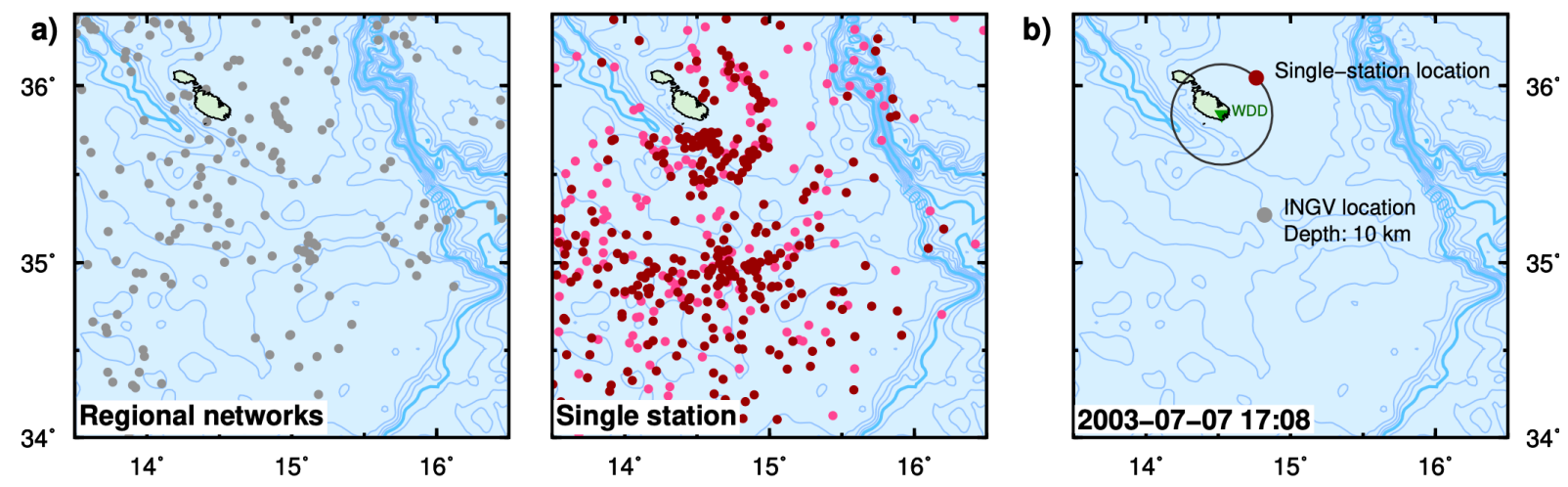

Figure 4. Comparison between earthquake bulletins of INGV and IRIS with single-station locations for the years 19952014. a) Epicentres listed in the bulletins of INGV and IRIS located using regional networks (left, grey dots) and epicentres estimated using station WDD only (right, red and pink dots). b) Example of location differences between single station (red dot) and regional network solution (grey dot) for the $7^{\text {th }}$ of July, 2003 earthquake (See earthquake waveform in Figure 2). Circle shows the epicentral distance from station WDD (green triangle) determined from the $S$ - $P$ time difference of about 4 seconds.

Establishing the accuracy of an earthquake location determined from a single station is difficult, particularly if the origin is also uncertain. We thus compare our best-located earthquakes (Quality A) with those listed in the regional bulletins of INGV and IRIS to quantify the performance of LESSLA and in turn determine an estimate for the uncertainty of the earthquake's location and magnitude in the region. These comparisons are presented as difference histograms in Figure 5. We find that the epicentral distances to WDD from network and single-station locations differ, in the majority (> 75\%), by less than $20 \mathrm{~km}$ (Figure 5), and that most of the solutions have a backazimuth difference of $<30^{\circ}$. The locations of most of the earthquakes are within $60 \mathrm{~km}$ of each other, with the ones located farthest away from WDD increasing in disagreement. This is likely because a small change in back-azimuth yields a larger location error with distance.

Similarly, we compare the magnitude solutions output from LESSLA with those from the regional networks. Seismic networks are expected to provide a more accurate magnitude measure because they are based on different estimates (seismic body and surface waves, amplitude and duration, etc.) and consider the average from many stations. For example, the earthquake on $24^{\text {th }}$ April 2011 (13:02:12 UTC) was estimated to be $4.4 \mathrm{M}_{L}$ from the single-station processing and estimated at 4.1 when using the data of regional networks [D'Amico, 2014]. 
Distance difference between earthquake locations and WDD
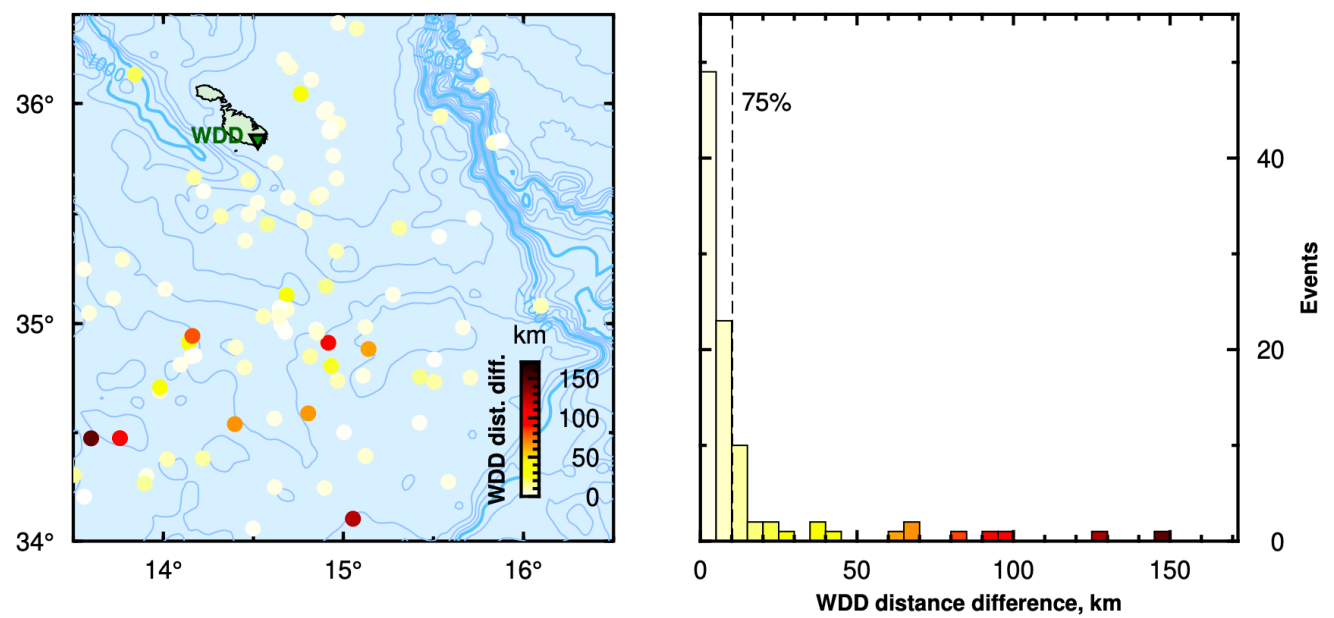

\section{Earthquakes locations back-azimuth difference to WDD}
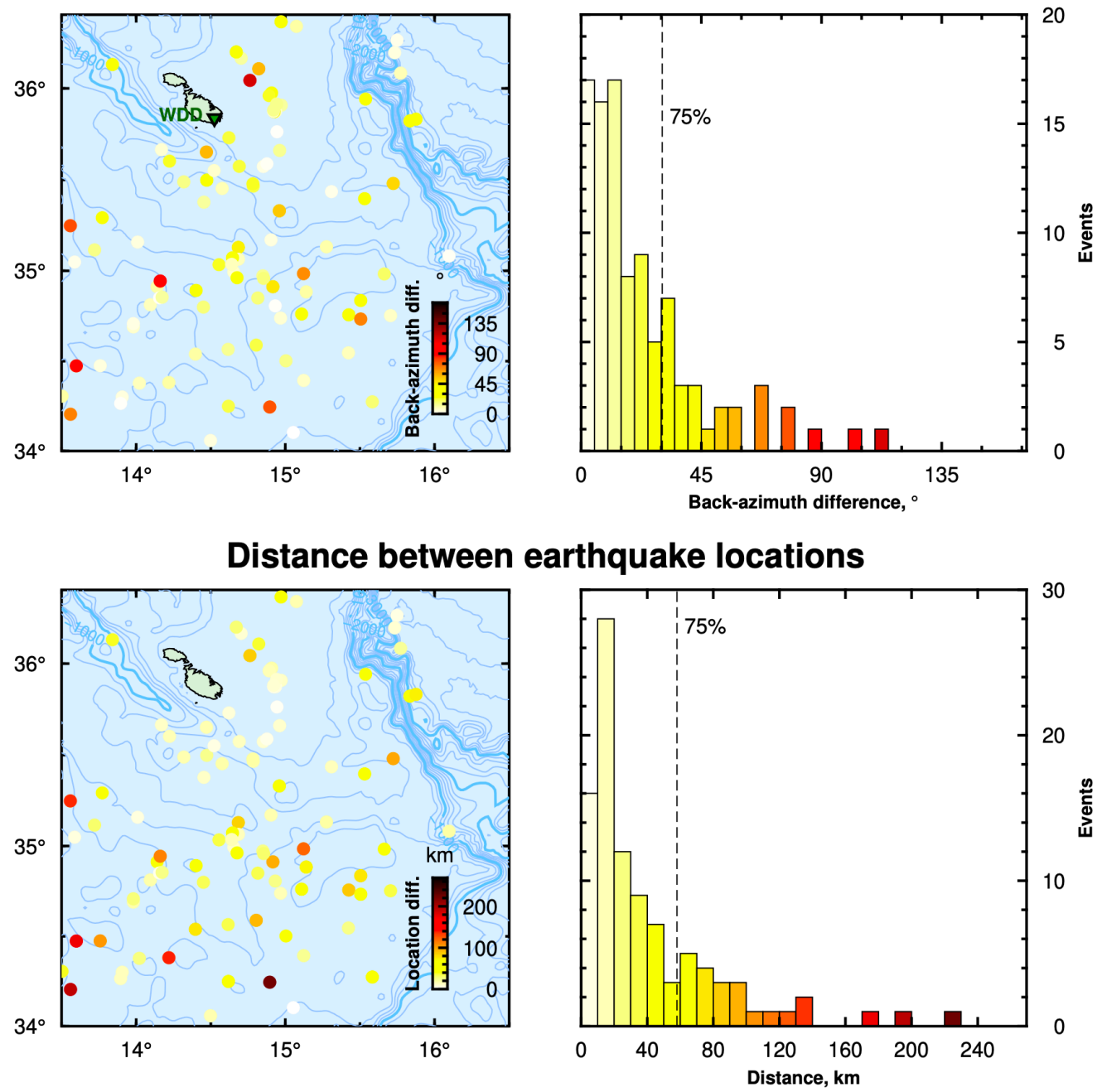

Figure 5. Example of earthquake location differences between epicentres published in the bulletins of INGV and IRIS, and the single-station locations. Plotted epicentres are quality A earthquake locations from LESSLA colour coded to indicate the respective differences between location from the regional network (INGV and IRIS). Histograms show the number of events for each binned difference, colour coded to match epicentres on the adjacent map. The dashed line marks the $75 \%$ of binned events. Top: Difference between network epicentre distance to station WDD and LESSLA epicentre distance to WDD. Middle: Station WDD back-azimuth difference between network epicentre location and LESSLA epicentre location. Bottom: Location difference between network and singlestation location. 
Magnitude differences between LESSLA and network solutions range from -0.6 to +0.8 for nearby earthquakes $(<100 \mathrm{~km}$ away from WDD), and from -0.6 to +1.4 for distant earthquakes, with both ranges peaking at +0.2 (Figure 6). This means that in most cases the magnitude computed using the single-station method (listed here) are higher by at least 0.2 . A re-calibration of the local magnitude formula for this particular region will be considered in a future work.
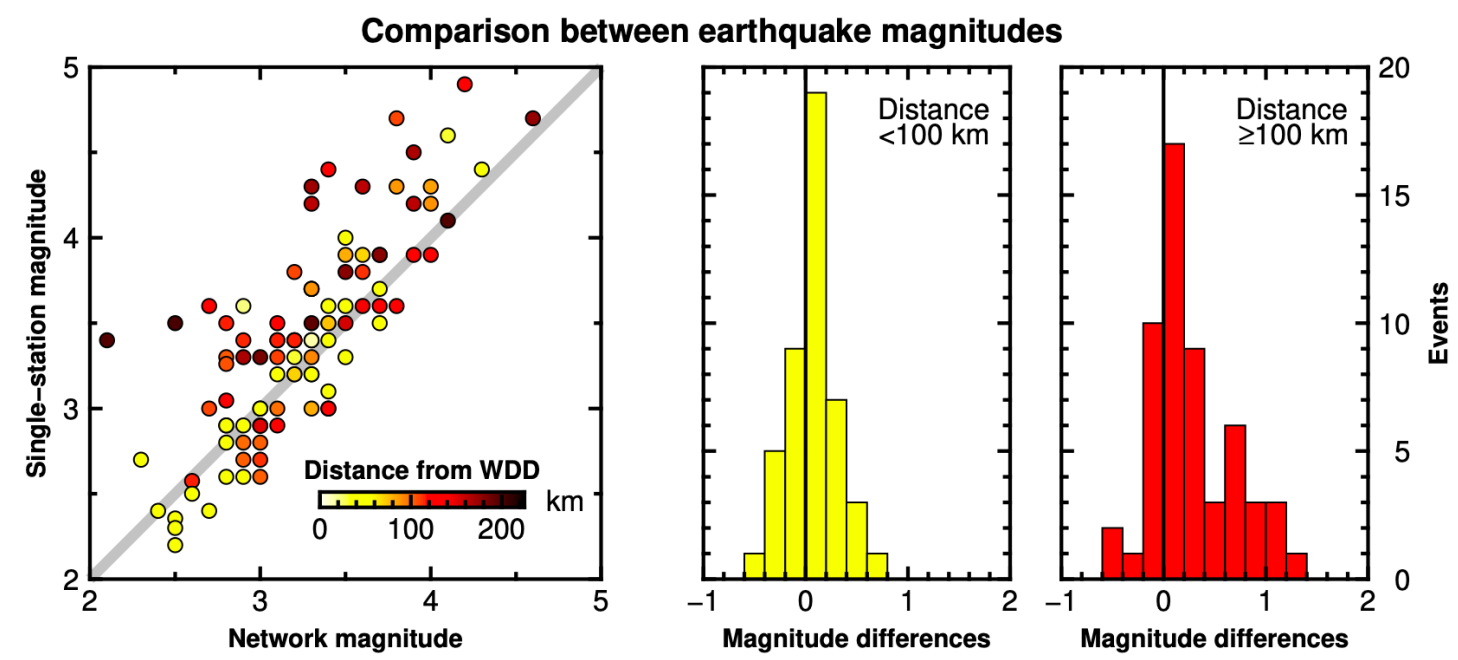

Figure 6. Comparison of earthquake magnitudes between single-station $\left(\mathrm{M}_{L}\right)$ and network estimates. The thick, grey line shows the expected one-to-one relationship between the two solutions. Overlapping coloured dots are unique earthquakes marked as good quality and have a corresponding network solution. The histograms show the distribution of the magnitude differences for local $(<100 \mathrm{~km})$ and regional earthquakes $(\geq 100 \mathrm{~km})$. Most of the single-station estimates tend to be 0.2 higher than network solutions.

Determining the depth of an earthquake using only a single station can, in theory, be inferred from the incidence angle of the $P$ phase, however, it is less robust than the back-azimuth estimation and requires detailed knowledge of near-surface stratigraphy. For this data set, we do not estimate the depth (hypocentre) and thus cannot compare with the network bulletins. We assume a surface focus keeping in mind that the radial distance from the station is overestimated in the case of deep events. Most of the earthquake depths listed in the INGV and IRIS bulletins are within the crustal depth ( $<25 \mathrm{~km}$ depth) with a few exceptionally deep earthquakes such as the earthquakes on 199610-27 (16:16:52 UTC) listed at $146 \mathrm{~km}$ depth, and 2014-10-31 (23:35:21 UTC) listed at $87 \mathrm{~km}$ depth. Unfortunately, at the time of these two listed earthquakes, there is no data from station WDD making it impossible to verify these depths. It is unlikely that an earthquake so deep occurs in this area of the Sicily Channel because the thickness of the crust is expected to be less than $25 \mathrm{~km}$ [Civile et al., 2008] and no subduction processes are taking place here. Such presumed errors in the bulletins are likely to increase our inaccuracy estimates presented in Figures 5 and 6.

\section{Earthquake catalogue}

We compile an earthquake catalogue for Malta for the years 1995-2014, covering the selected area between $13.5^{\circ}$ East, $34^{\circ}$ North and $16.5^{\circ}$ East, $36.4^{\circ}$ North. The northern, western and southern borders of the area are located approximately midway between Malta and the Italian national boundaries (Sicily and Linosa) and that of Libya (Figure 1) and the area coincides largely with the continental shelf area belonging to Malta. For completeness, the catalogue is a compilation of unique earthquake events combining our list from the single-station measurements and earthquakes listed in the INGV and IRIS bulletins. The INGV bulletin provides the list of earthquakes closer to the Italian territory, whereas the IRIS database is more complete for sources located towards the Libyan coast. Events with origin time within 1 minute of each other are assumed to be the same event. If an earthquake is found in more than one list, the following criteria were used: first preference was given to the epicentre located by LESSLA 
quality A waveforms, then to the INGV location and then to IRIS location. The depth estimated by the latter two network solutions is included. During periods when data from WDD was not available for any reason, the INGV locations were included. Poorly located earthquakes listed only by LESSLA and having quality B are included but marked as "poor".

We disregarded earthquakes which have epicentres potentially located onshore the Maltese islands for various reasons. First, LESSLA has a time window limit to calculate the back-azimuth accurately; the $S$ - $P$ time must not be less than the processing time windows of the streams otherwise risking having the coda of the $P$ phase being contaminated with the arrival of the $S$ phase. Secondly, the $S$ - $P$ distance calibration formula used in LESSLA is not applicable to very short epicentral distances. Thirdly, onshore epicentres listed in network bulletins are unlikely to be correct mainly due to the epicentre distance mismatch with the $S$ - $P$ time, and, also because such earthquakes would have been felt locally but were not. Lastly, considering the very small size of the islands and the errors attributed to the single-station method, epicentres might be easily mislocated from offshore to onshore.

In total, the catalogue includes 550 unique earthquakes. Of these, 308 earthquakes have good (confident) epicentre locations determined using single-station processing, 149 earthquakes of less reliable locations also processed using single-station analysis, and 93 earthquakes are from IRIS and INGV networks. The final list of earthquakes is available as Supplementary information (Table S1) and shown in Figures 7 and S4 (white box). The new dataset has significantly increased the detection of smaller magnitude earthquakes. This is quantitatively shown by the Gutenberg-Richter relationship between the magnitude and the total number of earthquakes located (Figure 8).

\section{Discussion}

The newly compiled earthquake catalogue for the Malta region contributes to a more complete data set for the Sicily Channel. We have located more than double the earthquakes listed in the conventional network bulletins and broadened the magnitude detection range for the area. Thanks to this new dataset we can now analyse the spatial and temporal seismicity taking place in the region in more detail.

It is immediately clear that the seismicity is neither as infrequent nor as diffuse as is generally assumed for the Sicily Channel (Figure 4), and it is possible to propose certain correlations between seismicity patterns and the general tectonic features of the region, as certain areas appear to be more seismically active (Figure 7 and S4). While the major boundary faults on the grabens themselves do not appear to be the most active regions, we note that the Malta graben appears to be active mostly at its south-eastern extremity, with a cluster of events occurring as close as $20 \mathrm{~km}$ from the coast of Malta. For this cluster, it is possible that the spread in azimuth represents the errors in the calculation of this parameter, and after consideration of this error, it is likely that the activity is confined to a small region at the south-east extremity of the Malta graben (Figure 7). Similarly, seismicity appears to occur along the southeastward extension of the Linosa Graben.

To the east of Malta, about $40 \mathrm{~km}$ offshore $\left(35.8-36.0^{\circ} \mathrm{N}, 14.8-15.0^{\circ} \mathrm{E}\right.$, Figure 7), there is another cluster of epicentres. This region is known to have generated sporadically occurring earthquakes, as was the case on the $24^{\text {th }}$ of April 2011, when a seismic swarm of around 15 events occurred over a period of 4 days (Figures 3 and S3). The largest event had a magnitude $>4$ and was clearly felt all over the archipelago, but especially on the eastern side of Malta [maximum felt intensity value of IV, Agius et al., 2015a].

The highest concentration of seismic activity appears to be clustered at 80-120 km SSE of Malta at the $35^{\circ}$ latitude (Figure 7). Typically, seismic activity in this region occurs episodically in swarms lasting a few days or weeks. These are visibly identified in the seismicity time evolution in Figures 3 and S3. The seismic activity at latitude $35^{\circ} \mathrm{N}$ coincides broadly with the east-west trending, dextral shear lineament referred to in Jongsma et al. [1985] and others. Seismicity to the south of $35^{\circ} \mathrm{N}$, on the other hand, appears spatially sparse, although this could reflect location uncertainty at this distance from WDD (Figure S3).

The consistent coincident locations of each earthquake in the respective swarm give us added confidence in the earthquake locations. Considering that the distance estimate ( $S$ - $P$ time) is our most robust measurement, in cases where the epicentral distance of earthquakes within a swarm event tends to vary regularly over time may be a result of rupture propagation taking place along the source-station distance or changes with the earthquake depth (Figure 3). A detailed seismic study using different types of wave analysis may make it possible to understand the mechanism and time evolution of these earthquakes and the swarms in general during the time of this activity. 


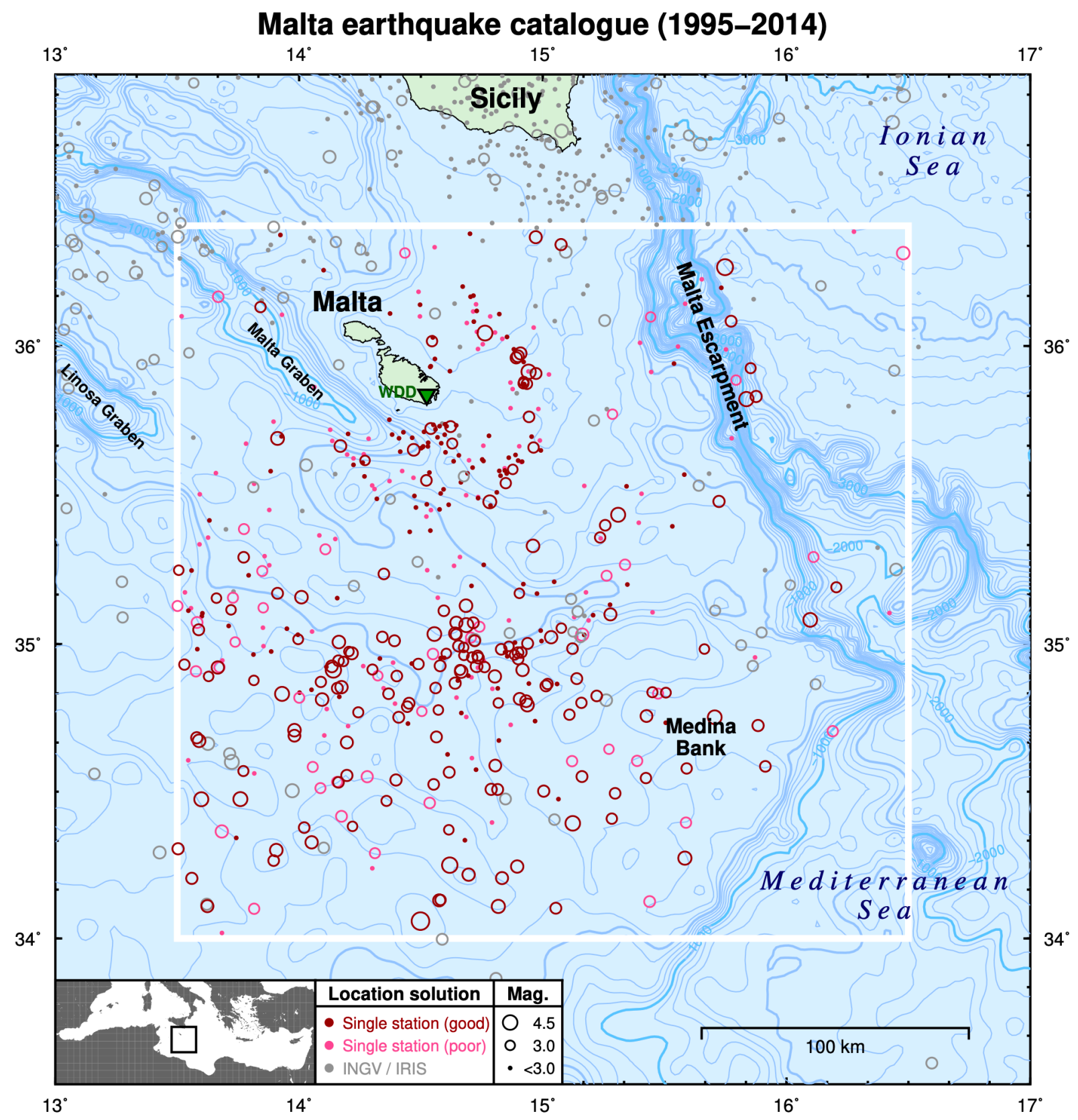

Figure 7. The earthquake catalogue for the offshore Maltese islands region, 1995-2014. Circles are unique earthquake epicentres located either by regional networks INGV or IRIS (grey), or by single-station (red and pink) $P$-wave polarisation analysis on station WDD (green triangle). The size of each circle corresponds to the magnitude of the earthquake. Red circles are robust locations; pink are poor locations. Thick and thin blue contours mark the depth at every 500 and 100 metres, respectively. White box indicates the study region considered for the Malta earthquake catalogue. Inset map shows the area on a regional map.

While it is not the purpose of this article to interpret the observed seismicity in terms of the neotectonics of the region, we point out that several studies of the kinematics and tectonics of the Central Mediterranean are necessarily missing an important component based on seismicity, because the earthquake activity is perceived to be sparse and/or of low magnitude. Indeed, seismicity patterns are often key to understanding plate boundary behaviour, particularly such a diffuse and complex boundary as in the Central Mediterranean. In this regard, we feel that these, and future enhanced observations, will add a new dimension in the unravelling of the present-day tectonics and kinematics of this region. Such seismicity data sets will be necessary to answer key questions such as: Why do the southward extensions of the grabens, particularly the Malta graben, appear to be more seismically active? Could this 
be representative of the present-day mode of propagation of the extensional rifting affecting the Sicily Channel? What can it tell us about the proposed models for new microplates in the region? How is this rift propagation related to the deepening throw of the grabens, and a corresponding increase in sedimentary infill thickness on going southeastwards [Corti et al., 2006]. Serpelloni et al. [2007] also observe that the sparse seismicity on the main grabens may be related to the high heat flow measured over the grabens [Della Vedova et al., 2001] and that deformation may, therefore, be occurring aseismically. It would be interesting to investigate whether the higher occurrence of seismicity towards the southern end of the grabens could indeed be a result of the cooler regime.

We have also investigated the magnitude-frequency distribution for earthquakes in the study region and time period by applying the Gutenberg-Richter relationship [Gutenberg and Richter, 1944]:

$$
\log N=a-b M
$$

where $N$ is the cumulative number of earthquakes of magnitude $M$ or greater, $a$ is constant, and the empirically determined $b$-value is typically about 1 .

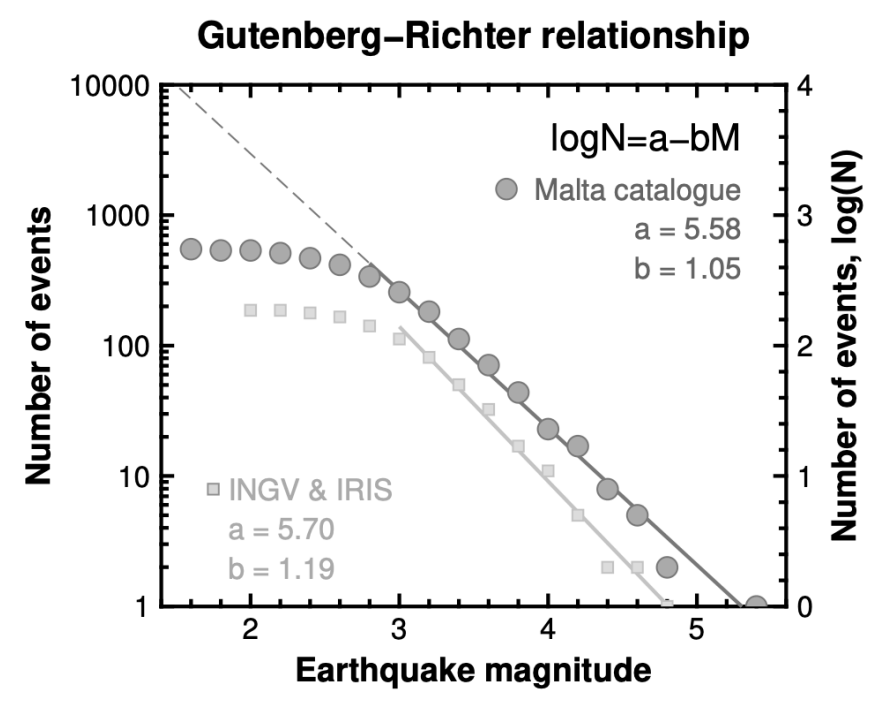

Figure 8. The Gutenberg-Richter power-law relation between earthquake magnitude and frequency. $N$ is the number of earthquakes in the region having magnitude larger than $M, a$ is a constant and $b$ is the slope of the log-linear relation ( $b$-value, grey line). Dark grey circles are the data from the newly compiled earthquake catalogue (this study). Light squares are the power-law relation using the earthquakes listed in the INGV and IRIS bulletins only.

Figure 8 shows the fitting of the G-R relationship to our data. We obtain a $b$-value of 1.05 , which is close to the global average, and typical of tectonically active regions. The magnitude level of completeness is 3.0. Calò and Parisi [2014] also obtain a $b$-value of 1.05 for the data set along the N-S separation belt of earthquakes at the western edge of the Malta and Linosa grabens, whereas Pondrelli et al. [2011] obtained 1.13 for the whole Mediterranean region. Our value of $b$ is here only indicative because (i) the period of observation is insufficiently long, (ii) it assumes we detected all the earthquake with magnitude $>3$, and (iii) because of unquantified errors in the magnitude calculation. The value of $a$, on the other hand, depends closely on the $b$-value and gives an indication of the maximum expected magnitude in the region. In our plot, this value is 5.3, although the 20-year long dataset may not be entirely representative of the seismicity in the area. Even though the value $a$ may be overestimated due to magnitude errors, our value is less than the effective maximum earthquake magnitude of 6.0 assigned to our study area by the Seismic Hazard Harmonization in Europe (SHARE) model [Woessner et al., 2015]. The measured maximum magnitude during the study period was 5.4 on 2012-07-03 (05:03:41 UTC) at the southern end of our region. Historically it is also likely that an earthquake of similar magnitude occurred very close to the western coastline of the archipelago in 1911, the estimation being based on damage reports on the island of Gozo and on instrumental and felt reports in southern Sicily [Galea, 2007]. 


\section{Matthew R. Agius et al.}

Overall, this earthquake catalogue provides important information for the regional seismic hazard assessment, particularly for the Maltese archipelago. The seismicity on the Malta graben, in particular, reveals ongoing active faulting as close as $20 \mathrm{~km}$ from the islands. This study considers only the time period 1995-2014, when only a single station was available on the Maltese islands. In subsequent years, observational seismology has been considerably enhanced by the establishment of the Malta Seismic Network [Agius et al., 2015b], currently consisting of eight broadband stations over the archipelago, the establishment of the virtual regional network of the Central Mediterranean, enabling easier processing of data from Sicily, the Pelagian islands, Tunisia and Malta, and the deployment of temporary seismic networks to conduct seismic experiments [e.g., FASTMIT, Bozionelos et al., 2020]. This development has two major benefits for earthquake observation. Firstly it drastically improves our capacity to observe very close offshore and onshore seismicity and microseismicity on the Maltese islands, and secondly, it will provide further constraints and validation of single-station epicentre locations, together with source mechanisms, and therefore contribute to a more accurate future seismotectonic map.

\section{Conclusions}

Earthquake location in the Sicily Channel, especially to the south of the Maltese islands, is a difficult task owing to the poor station coverage, especially on the North African side, together with the generally low energy of events occurring in the region. Nevertheless, using a single-station location algorithm on station WDD (Malta), a quantitative reappraisal of the amount of seismic activity over a 20-year period between 1995 and 2014 has been possible. We combine the earthquake bulletins of INGV and IRIS together with the earthquake list from the single-station processing to catalogue 550 earthquakes in the study region. Many of these earthquakes have been overlooked before but are now detected and located using the single-station analysis. In this process, we compile a national earthquake catalogue for Malta.

The performance of the single-station analysis was found satisfactory, with the majority of the earthquake locations differing by $<60 \mathrm{~km}$ from the epicentres determined from the regional networks, or much less $(<20 \mathrm{~km})$ for local distances to Malta. However, this is not always a single-station problem; in some cases, the epicentral distances of the network location to station WDD did not match with the data. The local magnitude determined from LESSLA for earthquakes within $100 \mathrm{~km}$ radius were found to differ between -0.6 and +0.8 from magnitudes determined using a network solution, with a peak at +0.2 .

From the compiled catalogue we find that i) the highest concentration of seismic activity is located $80-120 \mathrm{~km}$ SSE of Malta at the $35^{\circ}$ latitude (Figures 7 and S4); ii) the southeastward extensions of the Malta and Linosa grabens are seismically active, showing that extension in the Sicily Channel is ongoing; iii) $40 \mathrm{~km}$ to the east of Malta there is another cluster of epicentres, which have generated felt earthquakes in the past; and iv) many earthquakes take place in swarms. We also conclude that the earthquake catalogue for this region is complete down to magnitude 3.0 earthquakes and that this region has the potential of an earthquake with magnitude $>5$.

Studies on the seismicity in this region are expected to improve significantly thanks to the recent deployment of the Malta Seismic Network, which will make it possible to lower the threshold of detectability and determine additional parameters such as depth and focal mechanism of earthquakes.

Acknowledgements. The authors are grateful to two anonymous reviewers for the useful comments that helped to improve the manuscript. The study formed part of the SIMIT project (Integrated Italy-Malta Cross-Border System of Civil Protection; B12.19/11) and the SIMIT-THARSY (Tsunami Hazard Reduction System, C1-3.2-57) part-financed by the European Union under the Italia-Malta Cross-Border Cooperation Programmes, 2007-2013 and 2014-2020. The facilities of IRIS Data Services, and specifically the IRIS Data Management Center were used for access to waveforms, related metadata, and/or derived products used in this study. IRIS Data Services are funded through the Seismological Facilities for the Advancement of Geoscience and EarthScope (SAGE) Proposal of the National Science Foundation under Cooperative Agreement EAR-1261681. The INGV Web Services were used to retrieve the earthquake catalogue (http://cnt.rm.ingv.it/en/webservices_and_software). Earthquake catalogues were retrieved using ObsPy: A Python Toolbox for Seismology [Beyreuther et al., 2010]. Figures were made using Generic Mapping Tools (GMT) software [Wessel et al., 2013; Agius, 2018]. Matthew Agius has received funding from the European Union's Horizon 2020 research and innovation programme under the Marie Sklodowska-Curie grant agreement No 843696. 


\section{References}

Agius, M. R. (2007). Automatic earthquake detection and localisation from a three-component single-station. Master's thesis, University of Malta.

Agius, M. R. (2018). Getting Started with GMT: An Introduction for Seismologists, Springer International Publishing, Cham., 691-723.

Agius, M. R., S. D’Amico and P. Galea, P. (2015a). The Easter Sunday 2011 Earthquake Swarm Offshore Malta: Analysis on Felt Reports. In Earthquakes and Their Impact on Society, Springer International Publishing, 631-645.

Agius, M. R., S. D’Amico, P. Galea, and F. Panzera (2014). Performance evaluation of Wied Dalam (WDD) seismic station in Malta, Xjenza, 2(1):72-80.

Agius, M. R. and P. Galea (2011). A Single-Station Automated Earthquake Location System at Wied Dalam Station, Malta, Seismol. Res. Lett., 82(4):545-559.

Agius, M. R., P. Galea and S. D’Amico (2015b). Setting up the Malta Seismic Network: instrumentation, site selection and real-time monitoring. In Lombardo, G. and Panzera, F., editors, Establishment of an integrated Italy-Malta cross border system of Civil Protection: Geophysical Aspects, Aracne Editrice, 11-30.

Beyreuther, M., R. Barsch, L. Krischer, T. Megies, Y. Behr and J. Wassermann (2010). ObsPy: A Python Toolbox for Seismology, Seismol. Res. Lett., 81(3), 530-533.

Boschi, E. and A. Morelli (1994). The MEDNET program. Ann. Geof., 37(5), 1066-1070.

Bozionelos, G., P. Galea, S. D’Amico., M. P. Plasencia Linares, M. Romanelli, G. Rossi, S. Parolai, A. Vuan, M. Sugan and M. R. Agius (2020). An augmented seismic network to study off-shore seismicity around the Maltese Islands: The FASTMIT experiment, Xjenza, 7(2), 104-121.

Calò, M. and L. Parisi (2014). Evidences of a lithospheric fault zone in the Sicily Channel continental rift (southern Italy) from instrumental seismicity data, Geophys. J. Int., 199(1):219-225.

Catalano, S., G. D. Guidi, C. Monaco, G. Tortorici, and L. Tortorici (2008a). Active faulting and seismicity along the Siculo-Calabrian Rift Zone (Southern Italy), Tectonophysics, 453(1):177-192.

Catalano, S., G. D. Guidi, G. Romagnoli, S. Torrisi, G. Tortorici, and L. Tortorici (2008b). The migration of plate boundaries in SE Sicily: Influence on the large-scale kinematic model of the African promontory in southern Italy. Tectonophysics, 449(1):41-62.

Cello, G. (1987). Structure and deformation processes in the Strait of Sicily “rift zone”, Tectonophysics, 141(1):237-247.

Civile, D., E. Lodolo, D. Accettella, R. Geletti, Z. Ben-Avraham, M. Deponte, L. Facchin, R. Ramella., and R. Romeo (2010). The Pantelleria graben (Sicily Channel, Central Mediterranean): An example of intraplate "passive" rift, Tectonophysics, 490(3):173-183.

Civile, D., E. Lodolo, I. Tortorici, G. Lanzafame, and G. Brancolini (2008). Relationships between magmatism and tectonics in a continental rift: The Pantelleria Island region (Sicily Channel, Italy). Marine Geol., 251(1):32-46.

Corti, G., M. Cuffaro, C. Doglioni, C., F. Innocenti, and P. Manetti (2006). Coexisting geodynamic processes in the Sicily Channel. In Postcollisional Tectonics and Magmatism in the Mediterranean Region and Asia edited by Yildirim Dilek and Spyros Pavlides, Geological Society of America, 409, doi:https://doi.org/10.1130/SPE409

D'Amico, S. (2014). Source parameters related to a small earthquake swarm off-shore of Malta (Central Mediterranean). Develop. Earth Sci., 2:8-13.

Dart, C. J., D. W. J. Bosence, and K. R. McClay, (1993). Stratigraphy and structure of the Maltese graben system. J. Geol. Soc., 150(6):1153-1166.

Della Vedova, B., S. Bellani, G. Pellis and P. Squarci (2001). Deep temperatures and surface heat flow distribution, Springer Netherlands, Dordrecht, 65-76.

Devoti, R., A. Esposito, G. Pietrantonio, A. R. Pisani and F. Riguzzi (2011). Evidence of large scale deformation patterns from GPS data in the Italian subduction boundary. Earth and Planet. Sci. Lett., 311(3):230-241.

Dziewoński, A., T.-A. Chou and J. Woodhouse (1981). Determination of earthquake source parameters from waveform data for studies of global and regional seismicity. J. Geophys. Res., 86(B4):2825-2852.

Ekström, G., M. Nettles and A. Dziewoński (2012). The global CMT project 2004-2010: centroid-moment tensors for 13,017 earthquakes. Phys. Earth Planet. Int., 200:1-9.

Galea, P. (2007). Seismic history of the Maltese islands and considerations on seismic risk. Ann. Geophys, 50(6), 725-740.

Gardiner, W., M. Grasso, M., and D. Sedgeley (1995). Plio-pleistocene fault movement as evidence for mega-block kinematics within the Hyblean-Malta Plateau, Central Mediterranean. J. Geodyn., 19(1):35-51. 


\section{Matthew R. Agius et al.}

Goldstein, P., D. Dodge, M. Firpo and L. Minner (2003). SAC2000: Signal processing and analysis tools for seismologists and engineers. The IASPEI International Handbook of Earthquake and Engineering Seismology, 81:1613-1620.

Gutenberg, B. and C. F. Richter (1944). Frequency of earthquakes in California. Bull. Seismol. Soc. Am., 34(4):185-188. Jongsma, D., J. E. van Hinte and J. M. Woodside (1985). Geologic structure and neotectonics of the North African Continental Margin south of Sicily. Marine Petrol. Geol., 2(2):156-179.

Neri, G., G. Totaro, B. Orecchio and D. Presti (2018). What seismicity offshore Sicily suggests about lithosphere dynamics and microplate fragmentation models in the Central Mediterranean. Solid Earth Discussions, 2018:1-59.

Nocquet, J.-M. (2012). Present-day kinematics of the Mediterranean: A comprehensive overview of GPS results. Tectonophysics, 579:220-242.

Pondrelli, S., A. Morelli and G. Ekström (2004). European-Mediterranean regional centroid-moment tensor catalog: solutions for years 2001 and 2002, Phys. Earth Planet. Int., 145(1):127-147.

Pondrelli, S., A. Morelli, G. Ekström, S. Mazza, E. Boschi and A. Dziewonski (2002). European-Mediterranean regional centroid-moment tensors: 1997-2000, Phys. Earth Planet. Int., 130(1):71-101.

Pondrelli, S., S. Salimbeni, A. Morelli, G. Ekström and E. Boschi (2007). European-Mediterranean regional centroid moment tensor catalog: solutions for years 2003 and 2004, Phys. Earth Planet. Int., 164(1):90-112.

Pondrelli, S., S. Salimbeni, A. Morelli, G. Ekström, L. Postpischl, G. Vannucci. and E. Boschi, (2011). EuropeanMediterranean regional centroid moment tensor catalog: solutions for 2005-2008. Phys. Earth Planet. Int., 185(3):74-81.

Reuther, C. (1990). Strike-slip generated rifting and recent tectonic stresses on the African foreland (Central Mediterranean region). In Annales Tectonicae, volume 4, pages 120-130.

Reuther, C.-D. and G. Eisbacher (1985). Pantelleria Rift-crustal extension in a convergent intraplate setting. Geologische Rundschau, 74(3):585-597.

Richter, C. F. (1935). An instrumental earthquake magnitude scale, Bull. Seismol. Soc., 25(1):1-32.

Roberts, R. G., F. Cassidy and A. Christoffersson, A. (1989). Real-time event detection, phase identification and source location estimation using single station three-component seismic data, Geophys. J. Int., 97(3):471-480.

Scerri, T. (2001). Duration Magnitude Scale and Analysis of Seismicity around the Maltese Islands. B.Sc. dissertation, University of Malta.

Serpelloni, E., G. Vannucci, S. Pondrelli, A. Argnani, G. Casula, M. Anzidei, P. Baldi and P. Gasperini (2007). Kinematics of the Western Africa-Eurasia plate boundary from focal mechanisms and GPS data, Geophys. J. Int., 169(3):1180-1200.

Wessel, P., W. H. F. Smith, R. Scharroo, J. Luis and F. Wobbe (2013). Generic Mapping Tools: Improved Version Released, Eos, Transactions of the American Geophysical Union, 94(45):409-410.

Woessner, J., D. Laurentiu, D. Giardini, H. Crowley, F. Cotton, G. Grünthal, G. Valensise, R. Arvidsson, R. Basili, M. B. Demircioglu, S. Hiemer, C. Meletti, R. W. Musson, A. N. Rovida, K. Sesetyan, M. Stucchi and The SHARE Consortium (2015). The 2013 European seismic hazard model: key components and results, Bull. Earthq. Engin., 13(12). 